\title{
Para ler além da palavra: instrumentos para a análise do discurso político
}

\author{
Leonardo da SILVA (1) \\ Instituto Federal de Santa Catarina (IFSC)
}

\section{RESUMO}

Esta resenha discute criticamente a conferência Instrumentos Linguísticos para análise do discurso político proferida pelo professor Uli Reich no evento Abralin ao Vivo, em que o autor apresenta conceitos linguísticos do campo da pragmática formal que podem ser utilizados para compreender a configuração ideológica de textos ou enunciados. Mais especificamente, Reich apresenta os conceitos de fundo comum ou common ground (STALNAKER, 2002), Questions under discussion (ROBERTS, 2012), implicaturas convencionais (POTTS, 2005) e "mesa" (FARKAS; BRUCE, 2010), para então analisar trechos da reunião interministerial realizada em 22 de Abril de 2020 pelo governo de Jair Bolsonaro. Por meio da análise, o professor demonstra quais fundos comuns são projetados pelos discursos proferidos

OPEN ACCESS

EDITADO POR

Raquel Freitag

AVALIADO POR Beatriz Christino

DATAS

Recebido: 05/07/2020 Aceito: 04/09/2020 Publicado: 08/09/2020

COMO CITAR

Silva, L. (2020).

Para ler além da palavra: instrumentos para a análise do discurso político. Revista da Abra-

lin, v. 19, n. 2, p. 1-5, 2020. pelos interlocutores presentes. A fala de Reich, além de ser uma aula sobre o papel da Linguística na compreensão da atualidade, fornece subsídios para o desenvolvimento de uma leitura crítica do mundo.

\section{ABSTRACT}

This review critically discusses the conference Linguistic Instruments for the analysis of political discourse given by professor Uli Reich during the event Abralin ao Vivo, in which the author presents linguistic concepts from the field of formal pragmatics that may be used to unveil the ideology behind texts and utterances. More specifically, Reich presents the concepts of common ground (STALNAKER, 2002), Questions under discussion (ROBERTS, 2012), conventional implicatures (POTTS, 2005) and "table" (FARKAS; BRUCE, 2010), and then analyzes excerpts from the interministerial meeting held by Jair Bolsonaro's government on April 22 ${ }^{\text {nd }}, 2020$.

Through the analysis, the linguist demonstrates which common grounds 


\section{REVISTA DA ABRALIN}

are projected by the discourses of the interlocutors present in the meeting. Reich's talk, besides being a class about the role of Linguistics in the understanding of contemporaneity, provides us with tools for the development of a critical reading of the world.

\section{PALAVRAS-CHAVE}

Discurso político. Common ground. Questions under discussion. Implicaturas convencionais. Mesa. Pragmática formal.

\section{KEYWORDS}

Political discourse. Common ground. Questions under discussion. Conventional implicatures. Table. Formal pragmatics.

Como pode a Linguística nos ajudar a compreender o mundo em que vivemos? Na conferência intitulada Instrumentos Linguísticos para análise do discurso político, o linguista Uli Reich da Freie Universität Berlin apresenta possibilidades para a compreensão do caráter ideológico da linguagem. Neste sentido, o professor e pesquisador, que tem como foco de trabalho a Teoria e a Análise Linguística, nos instrumentaliza com ferramentas do campo da pragmática formal para esmiuçar o que "está por trás" ou mesmo implícito em discursos. Por meio do enfoque em discursos políticos no contexto brasileiro da pandemia, a apresentação demonstra como enunciados não apenas revelam, mas também reforçam visões de mundo.

De início, Reich apresenta os conceitos que utilizará em sua análise, deixando claro que é papel da Linguística escrutinizar os discursos de forma a "esclarecê-los" sem recomendar posições políticas. Seu objetivo principal é identificar que fundo comum - ou common ground (STALNAKER, 2002) - é projetado pelos discursos políticos. Neste sentido, o professor apresenta o conceito de common ground demonstrando como determinados enunciados carregam pressuposições que, por sua vez, revelam visões de mundo. Ao dizer, por exemplo, que "Até o rei da cocada parou de comer bolo de coco", a palavra "até" desencadeia a pressuposição de que não era esperada tal atitude do rei da cocada. O common ground diz respeito, então, a pressuposições, crenças ou "verdades" compartilhadas no ato comunicativo que são consideradas como dadas e que, portanto, ficam implícitas em determinado enunciado. Durante a comunicação, projetamos um fundo comum aos nossos interlocutores, ou seja, estabelecemos um lugar comum do qual falamos, uma espécie de visão de mundo ou conhecimento prévio que projetamos para quem nos ouve. É importante destacar, neste sentido, que o common ground não é o foco temático do ato comunicativo, já que ele diz respeito ao que está "no fundo" da conversa e a aquilo que é pressuposto compartilhado entre os interlocutores.

Sendo assim, para chegarmos ao common ground, Reich também destaca a importância de identificar as Questions under discussion (ROBERTS, 2012). Esta ferramenta analítica mostra que cada 


\section{REVISTA DA ABRALIN}

enunciado responde, de alguma forma, a uma ou mais perguntas (frequentemente implícitas). Neste sentido, identificar as questões ou perguntas implícitas no discurso auxilia no processo de compreensão do que propriamente se fala. O autor apresenta, ainda, o conceito de implicaturas convencionais (POTTS, 2005), que diz respeito às implicações que podem ser deduzidas a partir de um enunciado. Ao afirmar, por exemplo, que "O rei da cocada está gordo mas feliz", sugere-se que quem está gordo em geral não está feliz por conta do uso da conjunção adversativa "mas". Por fim, Reich apresenta o conceito de "mesa" (FARKAS; BRUCE, 2010), que se refere ao que está em questão no discurso, ou seja, ao que é posto de forma a construir um common ground na interação comunicativa. Para ele, a "mesa" seria a diferença entre as convicções individuais e as convicções comuns, ou seja, ela pode ser entendida como as conclusões ou visões compartilhadas entre os interlocutores a partir da interação.

Para demonstrar como identificar a configuração ideológica do discurso político, Reich apresenta uma análise de trechos de enunciados proferidos durante a reunião interministerial realizada em Brasília em 22 de Abril de 2020, e posteriormente divulgada em forma de vídeo pela imprensa. Esta reunião, realizada durante o contexto da pandemia no Brasil, tinha (ao menos supostamente) como objetivo discutir e identificar ações do governo brasileiro de enfrentamento ao Covid-19. O que a análise conduzida por Reich demonstra, no entanto, é que o fundo comum projetado pelos discursos proferidos durante a reunião evidencia visões de mundo que inclusive negam a intenção de combater a pandemia. Ao analisar trechos de falas de Walter Souza Braga Netto, Paulo Guedes, Jair Bolsonaro, Ricardo Salles, Gustavo Montezano, Tarcísio Gomes de Freitas e Campos Neto, Reich demonstra qual é o quadro político do governo Bolsonaro, ou que visões de mundo são compartilhadas por estes interlocutores.

Para empreender tal análise, Uli Reich identifica, em diferentes enunciados retirados da reunião em questão, quais são as questions under discussion (que definem o tópico da interação conversacional), as asserções e possíveis implicaturas convencionais (que correspondem ao que se diz ou ao que não se diz sobre o assunto), o common ground que o falante projeta ao ouvinte (ou seja, qual é sua representação de mundo) e, finalmente, o common ground projetado pelo enunciado (que é a representação de mundo modificada a partir da interação). O linguista demonstra, neste sentido, como o processo de identificar as pressuposições, os common grounds projetados e as implicaturas convencionais auxilia no processo de compreensão da configuração ideológica de enunciados e textos.

Ao analisar enunciados de Paulo Guedes, por exemplo, que afirma que a China deveria financiar um plano Marshall no contexto da pandemia, Reich demonstra que o político pressupõe que a China é a culpada pelos problemas provocados pelo novo coronavírus. No enunciado "A China deveria financiar um Plano Marshall para ajudar todo mundo que foi atingido", temos como Question under discussion "Quem deveria financiar o Plano Marshall?", a implicatura convencional de que a China é a culpada pela pandemia, o common ground de que "o culpado deve pagar" e que "alguém deve financiar o Plano Marshall" e, por fim, o common ground projetado de que a China, enquanto culpada, deve pagar pelo Plano Marshall (e que este plano é uma medida necessária neste contexto).

Reich também discute diversos outros enunciados utilizando os mesmos instrumentos linguísticos de análise. Ele demonstra que Guedes, ao afirmar que não há possibilidade de combate da 


\section{REVISTA DA ABRALIN}

desigualdade, mas que o governo deve "fazer o discurso" da desigualdade, projeta um fundo comum de que é preciso utilizar-se do discurso da desigualdade para reeleger o presidente. Já Bolsonaro, ao criticar a imprensa, diz:"se a gente puder falar zero com a imprensa é a saída", o que pressupõe uma compreensão de que os políticos devem evitar a imprensa. Campos reforça essa aversão à imprensa ao dizer que "quanto mais informação você tem mais medo você tem, porque a mídia joga medo", o que contraria o fundo comum de que em uma democracia a informação da imprensa é fundamental e projeta a visão de que é necessário evitar as informações da mídia porque elas afetam negativamente os negócios. Bolsonaro inclusive afirma que os meios de comunicação "inventam um racismo", o que nos leva a entender que seu discurso compartilha uma compreensão de que ele não é racista e que o racismo é uma invenção da mídia (e que a mídia mente).

Reich demonstra, neste sentido, que a projeção de um fundo comum não democrático é reforçada por falas de outros políticos, como quando Salles afirma que o momento em que o foco da mídia está no Covid é oportuno para "ir passando a boiada" e mudando. Em outras palavras, ele vê a pandemia como útil para os objetivos do governo e afirma que "não precisamos do congresso". Montezano segue a mesma linha ao afirmar que "É um momento muito oportuno para a gente aproveitar isso", projetando um fundo comum de que é possível atuar fora do controle democrático. Há, ainda, enunciados que projetam uma compreensão de que Bolsonaro é um grande líder ao compará-lo com Roosevelt e Churchill.

Ao empregar instrumentos linguísticos específicos da pragmática formal, Uli Reich demonstra o que está em pauta, ou o que está na "mesa" durante a reunião interministerial. Sua análise aponta que os enunciados políticos evidenciam visões de mundo em que: o discurso da desigualdade deve ser utilizado objetivando a reeleição, é necessário evitar as informações veiculadas pela mídia, a pandemia pode ser útil para o governo, o governo pode atuar de maneira antidemocrática, e Bolsonaro não é racista mas sim um líder exemplar.

Reich deixa claro que as conclusões de sua análise talvez não sejam novidades para a sua audiência. No entanto, a importância de seu trabalho está em exemplificar como a Linguística pode fornecer instrumentos para a análise de discursos de forma a demonstrar cientificamente o que está por trás do que se diz. Embora tanto a Análise do Discurso francesa como a Análise Crítica do Discurso apresentem diversas ferramentas para investigar o caráter ideológico sempre presente na linguagem, considero que o que Reich nos apresenta são instrumentos da pragmática formal que, ao serem empregados nas análises do discurso político, exemplificam uma espécie de exercício que um leitor (e cidadão) crítico pode (e deve) aprender a realizar ao buscar compreender os discursos que o cercam. Neste sentido, defendo que sua fala demonstra não apenas a relevância da Linguística para a compreensão da linguagem e da sociedade, mas também apresenta possibilidades para desenvolvimento de um olhar crítico, que pode inclusive servir como inspiração para professores interessados em promover dentre seus alunos, parafraseando Paulo Freire (2011), a capacidade de ler não somente a palavra mas também o mundo. 


\section{REVISTA DA ABRALIN}

REFERÊNCIAS

FARKAS, Donka e BRUCE, Kim B. On Reacting to Assertions and Polar Questions. Journal of Semantics 27, n. 1, p. 81-118, 2010.

FREIRE, Paulo. A importância do ato de ler em três artigos que se completam. 51ed. São Paulo: Cortez Editora, 2011.

INSTRUMENTOS Linguísticos para Análise do Discurso Político. Conferência apresentada por Uli Reich. [S.l., s.n.], 2020. 1 vídeo (1h 21min). Publicado pelo canal da Associação Brasileira de Linguística. Disponível em: https://www.youtube.com/watch?v=Yjpi1XV0M1Y\&t=459s. Acesso em: 05 julho 2020.

POTTS, Christopher. The logic of conventional implicatures. Oxford: Oxford University Press, 2005.

ROBERTS, Craige. Information structure in discourse: Towards an integrated formal theory of pragmatics. Semantics and Pragmatics 5(6): 1-69, 2012.(1996 version: OSU Working Papers in Linguistics 49. The Ohio State University.)

STALNAKER, Robert. Common ground. Linguistics and Philosophy, s.l., ano 25, p. 701-721, 2002.

https://doi.org/10.1023/A:1020867916902 